\title{
A modified analytical framework for describing m-learning (as applied to early grade Mathematics)
}

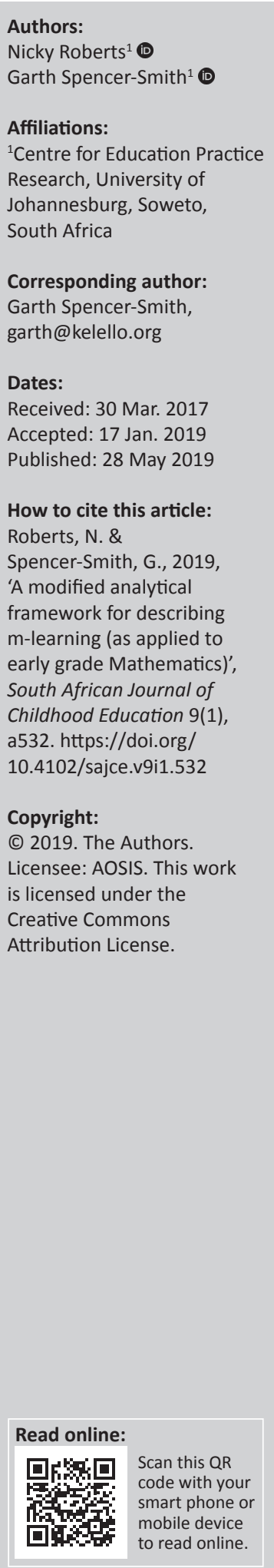

Background: There has been little Southern African research attention on the potentials of m-learning to support quality mathematics learning for young children and their caring adults. This article argues that $\mathrm{m}$-learning research has shifted from claims of being promising to claims of effect in educational settings of both classrooms and homes. This is particularly the case in mathematics, where there is increasing evidence of positive (although modest) improvement in learning outcomes.

Aim: This article modifies an analytical framework for initial descriptions of m-learning interventions. Comparison between interventions in the Southern African Development Community (SADC) context is then possible.

Setting: Three large-scale m-learning interventions focused on early grade mathematics in the SADC countries.

Methods: Targeting the early grades and building on an existing framework for describing m-learning interventions, three large-scale m-learning interventions from within the SADC were purposively selected. The three interventions exemplify a possible way to describe the learning theory and pedagogical emphasis underlying the design of their mathematics programmes.

Results: The cases themselves contribute to understanding the m-learning landscape and approaches to early grade mathematics in the SADC in more detail.

Conclusion: A modified analytical framework is offered as a means of describing m-learning in ways that attend to children's and caregivers' use of mobile devices, as well as the underlying learning theories.

Keywords: early grade; mathematics; m-learning; Africa; analytical framework; ICT.

\section{Introduction}

A relatively recent (2016) special issue of the South African Journal of Childhood Education had early childhood care and education (birth to 9 years of age), in disadvantaged contexts, as its focus. It was motivated by an urgent need to overcome the numerous risks facing young children and their families in vulnerable circumstances. In their editorial, Ebrahim and Pascal (2016) argued that:

[t]he way forward lies in focusing on teachers and their instructional practices and abilities to deal with contextual realities to forge navigational maps to improve the lives of children in vulnerable circumstances. (p. 2)

However, none of the interventions included in this special issue are related to teachers (caring adults or parents) and their instructional practices for mathematics. Neither did any of the interventions consider the possibility of utilising mobile technologies in this quest. We share Ebrahim and Pascal's (2016:3) urgency relating to young children and their families. We offer a focus on mathematics and m-learning as contribution towards their call 'to continue knowledge production about early care and education in a disadvantaged context, especially from the Global South' (Ebrahim \& Pascal 2016:3).

This article is based at the confluence of three educational premises relating to early education in the Global South: that improving mathematics and reading outcomes is a global priority; that early interventions are necessary to try and reduce the learning gap evident between children 
from wealthy and poor backgrounds; and that mobile learning is being looked to as a possible means for children and their caregivers to access better quality educational opportunities. Evidence supporting each premise is presented in brief.

Improving mathematics and reading outcomes is a global priority. The sustainable development goals articulate education as a global priority with 'Goal 4: Ensure inclusive and equitable quality education and promote lifelong learning opportunities for all'. The recent United Nations report (2018) on progress towards these goals has highlighted the progress with regard to increasing access to education, but laments the poor quality of learning in schools, noting that (Guterres 2018):

617 million children and adolescents of primary and lower secondary school age worldwide -58 per cent of that age group - are not achieving minimum proficiency in reading and mathematics. In 2016, an estimated 85 per cent of primary school teachers worldwide were trained; ... [where this is only] 61 per cent for sub-Saharan Africa. (p. 6)

The World Development Bank Development Report has echoed this concern, labelling it a 'global learning crisis' and reporting that 'schooling is not the same as learning', raising serious concerns about basic levels of literacy and numeracy which are most acute in lower income countries (World Bank 2018:45). Similarly, a United Nations Children's Fund (UNICEF) report on education in East and Southern Africa reports that ' 40 per cent of children in school do not reach the expected basic learning benchmarks in numeracy and literacy' (Friedman et al. 2016:6). This shifts the previous global priority on access to education towards improving learning outcomes for mathematics and reading.

Early interventions are necessary to try and reduce the learning gap evident between children from wealthy and poor backgrounds. The World Bank Development Report (2018) recognises that the shortfalls in learning occur early. It cites poor mathematics and reading outcomes that are evident already at Grade 2 level (World Bank 2018:5). The implications of this early learning gap in Southern Africa have been articulated clearly (Van der Berg 2015):

The policy message is simple and stark: for most children, learning deficits are already so substantial by the middle of primary school that many doors have already closed for them. Whilst efforts to ameliorate these deficits at higher levels are important and must continue for the sake of those who may still benefit from them, the greatest effort is required in the early school years, if not before. (p. 41)

Mobile learning is being looked to as a possible means for children and their caregivers to access better quality educational opportunities. There is a growing body of research directed to considering the educational benefits of m-learning. For example, several studies suggest that m-learning has the potential to extend education resources by opening access to disadvantaged peoples (e.g. women, homeless, offenders, disabled, sick and rural poor) and increase equity of access to education (e.g. Vosloo \& Botha 2009; Deloitte GSMA 2012), while others point to the instructional benefits of mobile phones (e.g. Daher 2010; Johnson, Adams \& Cummins 2012; Thomas \& Orthober 2011). Chee et al. (2017) completed a meta-analysis of m-learning trends from 2010 to 2015 and noted its successful use in a variety of education subject areas, including science, mathematics, language, art, social science and engineering. Crompton and Burke (2015) undertook a systematic review of 36 studies involving m-learning in mathematics and concluded that most of the studies reported positive learning outcomes.

Despite the growing evidence of efficacy of m-learning intervention in general, and in mathematics in particular, one has to question this evidence in terms of at least four aspects: (1) the limited scale of the studies on which the efficacy claims are made; (2) the extent to which they are representative of learning across the globe; (3) the absence of analytical frameworks that allow for comparison between different m-learning interventions; and (4) the lack of detail on their underlying learning theories and pedagogic practices.

Firstly, the very limited scale of studies included in m-learning meta-analyses is a concern. By way of example, in a recent systematic review of mobile and ubiquitous learning practices (drawing from 50 studies), Wong (2018:56) found that 'studies of mobile and ubiquitous learning practices mostly focused on specific courses with less than 100 participants'. Small-scale interventions which adopt an experimental design that draws on quantitative methods (where effect sizes may be compared) are used to make very general claims about effect. Yet, the details of exactly what the interventions entailed - their particular use of m-learning, and their approach to mathematics - are not provided.

Secondly, in relation to representation across the world, most studies of m-learning are based on research in developedworld contexts, specifically in countries classed by the World Bank (2018) as high-income countries. Chee et al. (2017) completed a meta-analysis on m-learning at all levels from pre-school to higher education, where they analysed all articles on m-learning published in the SSCI database from 2010 to 2015 in six leading educational technology-based learning journals, such as Computers $\mathcal{E}$ Education and the British Journal of Educational Technology. They found that a total of $77.1 \%$ of all the m-learning articles included were from high-income countries, with $20.1 \%$ from upper middleincome countries, $2.8 \%$ from lower middle-income countries and none from researchers in low-income countries. The only African countries mentioned in this article which have relevant output in this field were Nigeria and South Africa. A review of mobiles for early grade mathematics (SpencerSmith \& Roberts 2014) has helped to address the lack of evidence from developing country contexts as it provides an overview of mathematics project interventions in low- to middle-income countries. These interventions are mapped to the four focus areas of mathematics instruction and teaching and learning materials, teachers' professional development, learning outcomes assessment, and parents 
and community involvement. However, the Spencer-Smith and Roberts' (2014) review fails to describe the underlying learning theories and pedagogic practices of the m-learning interventions considered.

Thirdly, perhaps because m-learning is a relatively new research domain, there are very few common data collection tools and analytical frameworks for describing such educational interventions. Researchers tend to frame their enquiry in relation to experimental designs where m-learning interventions are contrasted to 'traditional' teaching interventions. These studies are then included in metaanalysis studies or reviews and judgements are made on whether or not m-learning for mathematics 'works'. For example, Cheung and Slavin (2013) found that educational technology applications in mathematics education generally produced a positive, though modest, effect (effect size $=+0.15)$ in comparison to traditional methods. By focusing on the new tool (mobile devices), the m-learning literature seems to ignore the history of educational theorising (where tools have long been used and have been evolving in educational settings and learning processes).

Finally, related to the above, studies on m-learning interventions may include a simple identification of the school subject which is in focus but seem to pay very little attention to orienting theories and underlying conceptualisations of how children learn in relation to that subject. The m-learning research does not sufficiently attend to what is (in our view) really of interest: the pedagogy underlying the intervention, how these m-learning tools have been utilised and what this reveals about the learning of young children.

This article makes a small contribution to starting to fill the gaps identified in m-learning research, particularly the paucity of evidence relating to m-learning in developing country contexts. It focuses on three large-scale (tens of thousands of learners), early grade (first 4 years of schooling) m-learning projects in the Southern African Development Community (SADC) countries $^{1}$ and maps these to a modified analytical framework for describing m-learning interventions.

\section{Research focus}

This article uses a simple definition of m-learning, as 'learning through mobile devices (such as smart mobile phones and tablet PCs)' (Chee et al. 2017:114). With this definition, m-learning may be used independently, by an individual or in a group; and m-learning may be a subset of 'blended learning': the combining of online and face-to-face instruction (Bonk \& Graham 2006:5). Notice that this does not refer to personal ownership of mobile devices, which is an alternative definition offered by Traxler (2009). We adopt the Chee et al. (2017) definition as personal ownership of mobile devices is

1.The following 15 countries are members of this grouping (in alphabetical order): Angola, Botswana, Democratic Republic of Congo (DRC), Lesotho, Madagascar,
Malawi, Mauritius, Mozambique, Namibia, Seychelles, South Africa, Swaziland, Malawi, Mauritius, Mozambique, Namibia, Seychelles United Republic of Tanzania, Zambia and Zimbabwe. not ubiquitous for young children or in most of the contexts in the Global South. In this context, where young children have access to mobile devices, this is often via parents, teachers or caring adults or via public institutions such as schools.

The purpose of this study is to refine a modified analytical framework that could be used to offer initial descriptions of m-learning interventions in similar contexts where the descriptions all attended to the same features.

This article answers the following research questions:

- How can a modified analytical framework for m-learning configurations be easily and cheaply used to develop common descriptions of m-learning interventions in SADC countries which utilise m-learning to focus on mathematics in the early grades?

- How can additional detail about the mathematical pedagogy underlying the interventions be easily and cheaply obtained from project coordinators?

In answering these questions, it was hoped that an analytical framework for describing m-learning interventions using a common set of spectra (defined in terms of m-learning configurations) would emerge.

\section{Analytical framework}

The analytical framework adopted for this study considers the m-learning configurations: the potential ways in which m-learning services are designed or intended for use by learners. We briefly describe each configuration in turn with reference to the literature informing them.

Strigel and Pouezevara (2012) identify three m-learning configurations: a learning spectrum which ranges from highly formal (in class, in school) to informal (learning for pleasure or entertainment); a kinetic spectrum which ranges from the learners being stationary to being mobile; and a collaborative spectrum (from individual to collaborative). Roberts et al. (2015) make use of these m-learning configurations to classify the Nokia Mobile Mathematics service which, although not an early grades intervention, still provides a useful SADC-based example to illustrate the way in which this m-learning configuration framework has been applied previously:

This [Nokia Mobile mathematics] mobile mathematics service was informal (used out-of-school) but supported formal learning (school mathematics) in terms of learning spectrum ... The service was towards the mobile end of the kinetic spectrum as the service could be used while the learners ... [were] moving ..., although this movement was not a requirement for engaging with the service. Finally, in terms of the collaborative spectrum, the service was nearer to the individual end of the spectrum ... [in that] individual learners typically worked independently on the service. However, the service included a limited collaborative aspect in that the learners' points (attainment and activity levels) were visible to each other in a community of mathematics learners, and learners could send messages to other learners from within the service. (Roberts et al. 2015:4) 
Roberts et al. (2015) argue further that two additional spectra ought to be added to the m-learning configuration framework: an 'access and affordability' and a 'mathematical pedagogy' spectrum. They motivated for and explained the former spectrum (access and affordability) as follows:

In the resource-constrained context of South Africa, where consideration of m-learning interventions should focus on redress and equity; we consider this spectrum to be a fundamental consideration. We think that this ranges from free public access to suitable devices and free broadband data on one end, to Bring Your Own Device (BYOD) access models and private individual data contracts for broadband data on the other. Subsidised data (by government or operators) and public investments into improved access to mobile devices fall somewhere on this spectrum. (Roberts et al. 2015:10-11)

In putting forward the mathematical pedagogy spectrum, Roberts et al. (2015) noted that none of the grey literature and documentation on $\mathrm{m}$-learning projects made explicit their theory of learning or articulated their approach to mathematics teaching. This was considered a serious omission as the underlying approaches to how learning and teaching take place ought to significantly inform the programme design.

These arguments are made with specific reference to South Africa, but the concerns raised in this context are relevant to the SADC community, where other member countries are also resource constrained when compared to the Global North.

The modified analytical framework put forward in this article builds on the work of Strigel and Pouezevara (2012) and Roberts et al. (2015). The previously suggested access and affordability spectrum has been separated to distinguish access (to a suitable device) from affordability of using the service (considering subscription and data costs). The accessibility spectrum ranges from free public access to devices by individuals (e.g. through the roll-out of devices to a school or schools), to free access to devices to be shared by pairs or groups of learners and to a 'bring your own device' (BYOD) model. It is assumed that access to the device (hardware) includes the requisite access to the learning platform (software). Whether the devices are accessible in school or outside of school is another consideration, which links to the learning spectrum. The affordability spectrum ranges from the free provision of data or the zero-rating of a mobi-site to a subscription model where users or schools have to pay for their data usage. Zero-rating (or in some cases offering an education rate) may be negotiated with individual mobile operators or could be an explicit legislative requirement of mobile operating licenses.

In terms of the mathematics pedagogy spectrum, the proposed range is from unarticulated pedagogy to a detailed, coherent pedagogy. However, it is worth unpacking this further to get a deeper understanding of precisely what component(s) of mathematical pedagogy is or are being foregrounded in the mathematics of the intervention. We argue that the components based on the work of Kilpatrick, Swafford and Findell (2001) are useful starting points for engaging project coordinators in their underlying theoretical approaches. Kilpatrick et al. (2001) offer five strands that define mathematical proficiency:

1. Conceptual understanding: the integrated and functional grasp of mathematical ideas, to enable learners to learn new ideas by connecting those ideas to what they already know

2. Procedural fluency: the skill of carrying out procedures flexibly, accurately, efficiently and appropriately

3. Strategic competence: the ability to formulate, represent and solve mathematical problems

4. Adaptive reasoning: the capacity for logical thought, reflection, explanation and justification

5. Productive disposition: the inclination to see mathematics as sensible, useful and worthwhile, coupled with a belief in diligence and one's own efficacy

These strands (or slight variations on them) have been adopted in several international curricula - including Australia, the United States, Singapore and Malaysia (Groves 2012). They feature in South Africa's recently published Teaching and Learning Framework for Mathematics (DBE 2018).

The five strands are mutually supportive and interconnected (hence Kilpatrick et al. 2001 refer to them as strands in a rope). Yet, different mathematics interventions place different emphasis on particular strands. Focusing on these different levels of emphasis in relation to an approach to mathematics teaching and learning can be informative. As such, the relative emphasis placed on the five strands may be used to classify an m-learning intervention's articulated approach to mathematics.

Figure 1 summarises the m-learning configurations.

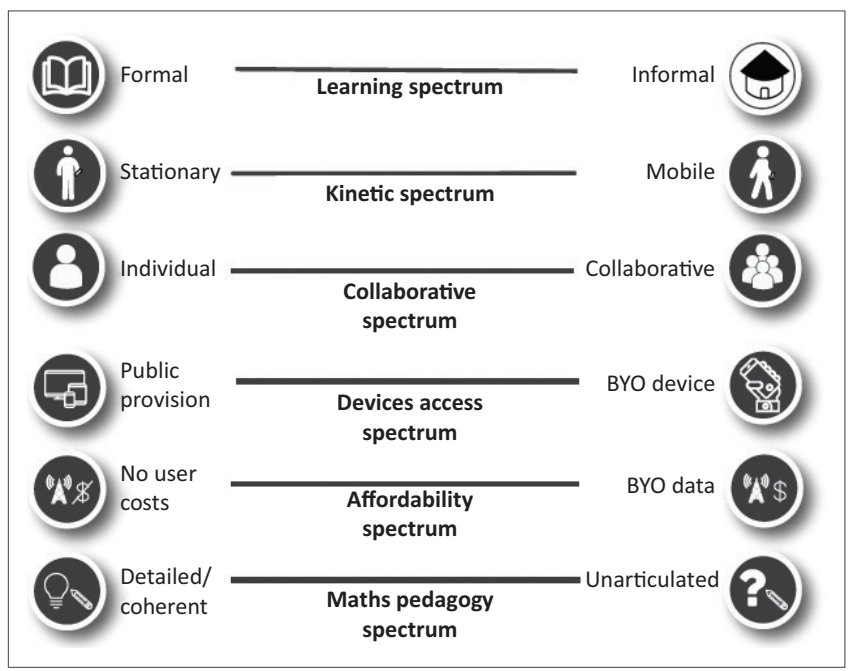

BYO, Bring Your Own

FIGURE 1: Analytical framework for m-learning configurations. 
Consideration is also given to the relative importance placed on the five strands of mathematical proficiency.

These strands are not on a continuum as the categories are not in a sequence.

\section{Methods}

To select the cases for inclusion in this article, the authors drew on, and then extended, empirical research work initially collected for the Spencer-Smith and Roberts (2014) landscape review of m-learning interventions in resource-constrained contexts. This review excluded proprietary services where users were expected to pay for use of the service. SpencerSmith and Roberts (2014) identified a total of 24 projects from 12 countries that met the four criteria of the study scope (m-learning, focused on mathematics or numeracy, and in early grades in low- to middle-income countries). Nine of these 24 projects were based in SADC countries, and three of these were selected to exemplify the modified m-learning analytical framework in this article.

The three projects were selected from the landscape review based on there being sufficient grey literature of their project documentation and support from the project coordinators to participate in the new research study. The three focal projects are: Mwabu in Zambia, Mathematics Curriculum Online in South Africa and Unlocking Talent in Malawi.

In 2016 and 2017, the project coordinators who participated in the Spencer-Smith and Roberts (2014) landscape review study were approached via email and requested to participate in this further phase of research. If they indicated willingness to participate, a draft updated synopsis of their intervention was presented to them (or their Chief Executive Officers) for further revision and refinement. All parties responded by providing feedback, which was used to update the project descriptions. Participation in the research was viewed in a positive light and the project coordinators welcomed the use of their names, and the project names, in a journal article. Inclusion was seen as a way of giving their project coverage in a peer-reviewed academic journal and academic exposure for their organisation, funders and others wanting to know about their initiative. As such, neither the projects nor the project coordinators have been anonymised.

Coding and analysis of the updated project data was then conducted making use of the modified analytical framework. For all the spectra (except the detailed considerations for mathematical pedagogy), the second author classified the project interventions against the analytical spectra. This was based on the project description and grey literature. This coding was blind-checked by the first author, and no changes in classification were made. The project coordinators were then presented with the way in which their intervention had been coded for each spectrum in the modified analytical framework. Once again, the project coordinators were invited to validate or change how their intervention had been coded. Some engagement was necessary over the 'learning spectrum', when interventions were in support of the formal school curriculum, but where use of the intervention took place outside of school time. The 'collaborative spectrum' also required some discussion, as in some cases the usual way of engaging with the content was individual although collaboration was possible (or vice versa).

For the mathematical pedagogy considerations, a different approach was required, as no descriptions of mathematical pedagogy were available in the grey literature. As such, the project coordinators were invited to respond to the following two questions via email:

- Please describe, in 3-4 sentences, the mathematical pedagogy underlying your intervention/service (this aims to capture how you approach the teaching and learning related to the mathematics of the service).

- Which two of Kilpatrick et al.'s (2001) five strands of mathematical proficiency ${ }^{2}$ do you feel that your service or intervention places more emphasis on? Please explain your answer.

While it was expected that all five strands may feature within a single project, how the project coordinators prioritised these was considered revealing of their emphasis and hence their pedagogic approach.

The purpose of this study was, however, to refine a modified analytical framework which could be used to offer initial descriptions of m-learning interventions in similar contexts where the descriptions all attended to the same features. Its intent was therefore limited to the project description level, and there was no intention to make evaluative comment on efficacy or impact (which would require far more empirical work). The data collection was limited to grey literature and direct engagement with the project coordinators.

\section{Ethical considerations}

This research drew on secondary sources available in the public domain to select possible case study projects. The project coordinators were then contacted via email and asked for their voluntary participation in the research. Upon their agreement, the case descriptions were circulated back to the project coordinators for validation (on three different occasions over time). No empirical data at the level of children were collected. As such, this research applied the ethical principles of voluntary, informed consent for research participants.

\section{Findings}

In this section, we offer a brief description of each of the three exemplar projects, followed by an application of the modified analytical framework.

2.These were provided in full to each respondent as part of the question, but have been removed here as they have been explicated earlier in the article. 


\section{Descriptions of the three cases}

Mwabu (previously known as iSchool) began with a pilot study in Zambia in 2010 but continues to date reaching over 200000 learners (this figure is for all primary grades and not specifically numeracy or mathematics) in more than 100 schools. Mwabu has created multimedia, interactive, localised eLearning content across the entire Zambian primary school curriculum. This is available on the fully-preloaded Mwabu tablet, designed to be a low-cost low-power device (which can be charged off solar power) that will work in any environment. Learning for all lower grades is in eight of the main local languages, as well as in English. Teachers have access to over 5000 lesson plans covering mathematics and all other subjects designed to help teachers provide detailed, interactive lesson plans covering every school day for every primary grade. In the future, content will be accessible via an application and via other non-proprietary tablets, both on Android and Microsoft operating systems. Mwabu is now also working in other SADC countries, such as South Africa and Lesotho (C. Rebe, Mwabu, pers. comm., 11 June 2018).

For the Mwabu project, learning takes place in school during mathematics lessons and supports the formal school curriculum. ${ }^{3}$ Learning takes place in classrooms while the learners are stationary. Engagement is primarily individual, although some face-to-face collaboration is possible. A device is provided to each learner; no data is required, and there are no subscription costs. The intervention prioritises conceptual understanding and procedural fluency.

Mathematics Curriculum Online (MCO) is a project implemented by Green Shoots in South Africa, targeting Grade 3 to $7^{4}$ learners in Mathematics by means of an online resource that is device neutral. Mathematics Curriculum Online encompasses a structured, weekly programme of Mathematics exercises that cover the key concepts and assessment objectives of the Mathematics Curriculum and Assessment Policy Statement (CAPS), real-time feedback and customised data analysis to key stakeholders within the education system. Mathematics Curriculum Online started in 2012 with eight schools; by June 2018, there were 105000 learners and 2300 teachers at over 277 schools registered to use it (J. Besford, MCO, pers. comm., 12 June 2018).

The Mathematics Curriculum Online project learning takes place in school time during mathematics lessons and supports the formal school curriculum. Learners are stationary while engaging with the mathematics content. Most of the interaction with the device is individual, although there is the potential for collaboration. Because of there being a limited number of devices per class, the weekly 'Brain Quests' are completed collaboratively (with two learners per device); however, the 'Formal Assessment Tasks' are completed individually. Schools use devices supplied by the provincial education department, by a donor or by the schools 3. However, there is also an informal version of Mwabu for home learning.

4.Thus, their target learners are only partially in the early grades. themselves. Data costs are paid by the school or as part of a Provincial Education Department initiative. There are annual subscription costs for Mathematics Curriculum Online that can be paid by the school or as part of a wider Provincial Education Department or donor programme (most are paid by Education Districts within the provinces as part of their mathematics curriculum programmes). The intervention prioritises procedural fluency and productive disposition.

The Unlocking Talent project, implemented by Voluntary Service Overseas (VSO) International in Malawi, began in late 2013 and is being scaled up. It is now operating in 50 schools in 9 districts, with secured funding to date for 128 schools in 15 districts. The current reach is approximately 20000 Standard 1 and 2 learners, with a planned reach of more than 55 000. This project uses digital educational technology (the Apple iPad Mini locked to the Masamu app ${ }^{5}$ ) and numeracy content for Standards 1 and 2 that is aligned with the Ministry of Education curriculum. Learners use the technology in a solar-powered learning centre at the school, which houses the tablets (Pitchford 2014; V. Shimizu, Unlocking Talent, pers. comm., 04 November 2016).

For the Unlocking Talent project, learning takes place during formal schooling while learners are stationary. The learning centre where the devices are accessed is another classroom in the school. Most engagement happens individually, although there is opportunity to collaborate. Learners are provided with both a device and the data required to access the service. There are no subscription costs. The project prioritises conceptual understanding and procedural fluency.

\section{Reflections on the use of the analytical framework}

The project descriptions included reference to the reach of the intervention in relation to the number of learners, geographic spread, technology used and implementation partners. Developing the project descriptions was not timeconsuming, and there were only minor changes requested from project coordinators or managers. In one case, there was a name change and a new website to consult; in all cases, the reach of the project required updating.

The original coding of interventions to particular spectra was largely uncontested; however, the spectra were not binary, and finding middle ground to reflect combinations and their relative weighting required some further engagement. This was anticipated and was the motivation for referring to the dimensions under consideration as 'spectra': these were not expected to be binary 'either or' categories, but the contrasting poles were designed to solicit engagement about particular aspects of the mobile learning configuration. For example, the learning spectrum with support of formal schooling on one end and informal learning on the other required more detail. The Mwabu project had both a formal version for children to use in school and an informal version for their use at home with caring adults. The project was therefore described as 5.These are mathematical apps provided by 'onebillion'. 
'out-of-school but formal' as in both cases the content aligned to and supported the formal school curriculum. Similarly, more nuance was sought in reflecting on the kinetic spectrum, where an initial coding of the Mwabu project as 'stationary' was contested:

This is not necessarily the case as many sessions require the children to do active things when working in their maths work (for example, making a market stall and 'playing markets' with pretend money). This is described as an activity to the teacher who then enables this to take place in the classroom. There are, however, also static learning elements on the tablet where a pair of children are working on a learning content with one tablet and are interacting with the learning through questions on screen. The children need to work to answer these quiz questions sometimes on the tablet and sometimes in their books. (C. Stead, Mwabu, pers. comm., 06 October 2016)

With this feedback, we noted that there were 'mobile moments' within the service design and requested an estimate of what percentage of the time spent on the service involved learners moving (and not just being at their desk). It was then explained that:

[T] he children will be counting using beans, or stones; so active but at their desks! This is encouraged a lot, so this level of doing is encouraged about $50 \%-60 \%$ of tasks. However, the big active sessions are probably a lot less frequent. (C. Stead, Mwabu, pers. comm., 11 October 2016)

So, 'big active sessions' involving, for example, the market stall with teacher-initiated activity involving the children moving around were estimated at 'say, $10 \%$ of activities' (C. Stead, Mwabu, pers. comm., 11 October 2016).

In relation to the second research question about the mathematical pedagogy underlying the interventions, we provide the project coordinator responses to the two questions posed, in full.

For $\mathrm{Mwabu}$, the project coordinator responded to the request for 3-4 sentences describing the mathematical pedagogy underlying their intervention or service as follows:

The mathematical pedagogy in our product is based on active, enquiry-based learning, where children are taught maths both as a set of skills, knowledge and understanding, but also as part of their wider learning. For example, in Year 4, when learning about 'the Island' as a topic, the children are asked to prepare plans to help the builder build a new school, they need to use length and measure to complete the tasks as well as area and perimeter. In year two, the children learn about the market, and during that topic, make a market stall and apply their newfound knowledge in money to running their pretend shop. (C. Stead, Mwabu, pers. comm., 04 October 2016)

The Mwabu project coordinator prioritised conceptual understanding and procedural fluency, although recognised that the other strands feature to some extent as well. This prioritisation was explained as follows:

Conceptual understanding is key. Without this, the children will not have understood the concepts being taught and will not be able to apply the learning to other areas of the curriculum or life.
The second area which we most highlight would be procedural fluency, the knowledge of how to solve maths problems, [and] how to check their answers is key. We would however also encourage our teachers, as they develop their own skills to work on the strategic and adaptive reasoning as well. Ultimately, we want the children to have a productive disposition, but we would have to assume that many teachers were working towards the last three levels [of Kilpatrick et al.] at this stage. (C. Stead, Mwabu, pers. comm., 04 October 2016)

The MCO Director responded to the request for 3-4 sentences describing the mathematical pedagogy underlying their intervention or service as follows:

Maths Curriculum Online provides weekly consolidation exercises 'Brain Quests' that are exactly mapped to curriculum content for that week. The Brain Quests provide examples of multiple questions styles of increasing difficulty. This structure supports teachers to cover the entire curriculum at the correct pace and level and to the depth required. Assessment for learning is enabled through the real-time per learner, per question feedback summaries. Teachers are able to address barriers to learning or identify learners with specific issues within the same lesson or amend subsequent lessons. Learners can immediately assess their progress. The feedback provides learners a sense of achievement and this improved confidence is transferred back to paper-based Maths activities/assessments. The termly online assessment summary data encourages collaboration within a grade or a phase, as teachers work together to tackle common issues or share specific interventions that they have trialled. (J. Besford, MCO, pers. comm., 03 October 2016)

Here, tight alignment for curriculum structure that follows a tightly defined weekly 'curriculum pacing' is the main focus of attention, as well as assessment for learning that aligns to this policy framework. Of the five strands of mathematical proficiency, the Mathematics Curriculum Online coordinator prioritised procedural fluency and productive disposition. In relation to the former, they elaborated that:

The real-time, auto-marking allows learners to practice, check answers and the[n] immediately review their thinking if incorrect. Learners are exposed to many question styles that allow them to develop processes to apply their understanding to a range of situations. Auto-marking requires accuracy of answers (J. Besford, MCO, pers. comm., 03 October 2016).

With regard to prioritising productive disposition, they indicated:

Learners are encouraged to review their scores, look at where they struggle, seek assistance. For many it is the first time a personal, active participation in Maths is promoted. The use of technology to deliver activities coupled with the immediate feedback has encouraged a level of engagement and achievement that was not necessarily generated previously. (J. Besford, MCO, pers. comm., 03 October 2016)

The Unlocking Talent project coordinator responded to the request for 3-4 sentences describing the mathematical pedagogy underlying their intervention or service as follows:

In maths, concepts and skills build on each other, with increasing levels of difficulty. It is harder to count to 20 than to 10 . It is harder to calculate $47+12$ than $5+2$. It is harder to subtract than 
to add. So, our approach is three-fold: (1) use familiar objects (fruit, flowers, cups, fish) to introduce concepts where possible; (2) build up the work slowly, at each stage showing the child 'how to' and (3) offer different approaches where feasible, for example number lines for addition. We also aim to make the activities engaging and fun. (V. Shimizu, Unlocking Talent, pers. comm., 05 November 2016)

In terms of the five strands of mathematical disposition, in the case of Unlocking Talent, conceptual understanding and procedural fluency were emphasised, with each being explained in detail:

Conceptual understanding. We begin very simply, using familiar objects to introduce concepts. We build each concept in stages, and revisit concepts at increasing levels of difficulty, as a classroom teacher would. For example, addition and subtraction are first introduced by simply adding and taking away items by touching the screen, and counting the resulting set, without the symbols,+- , and $=$. These are introduced in later units, with staged explanation. We move from concrete to abstract only when a concept is well established. We design with simplicity in mind. We cannot afford to leave the child confused, and particularly if there is nobody around to intervene and offer help. Most importantly, we use no text, except for very infrequent labels (e.g. on 2-D shapes). So, progress in reading is not an issue. All explanations and instructions are in audio, and we keep the audio simple and short. We try to put ourselves in the child's place and track the child's thought processes.

Factors that might interfere with understanding include screen layout and the amount of material on screen. We work to ensure that screens look legible and uncluttered. This is often quite a challenge, for example where we show an array of 100 items.

The technology itself is a wonderful aid to conceptual understanding. By simply touching the screen, the child can add an object to a set. By touching an object, the child can take it away. The child can drag a missing number into a sequence or move an object from one place to another.

We do our best to exploit what the technology offers. By means of the pointing hand - our little teacher's hand - and highlighting, and other colour changes, we draw attention to what is going on and help the child to focus closely. Other animations, and sound effects, help too.

Overall, the tablet can often offer more help in conceptual understanding than a busy teacher can - and especially a busy teacher with limited resources and a large class. For example, the teacher may have few objects to hand with which to explain subtraction. But on the tablet the child can subtract at the lightest touch, and from a wealth of objects. (V. Shimizu, Unlocking Talent, pers. comm., 05 November 2016)

The emphasis on procedural fluency was also elaborated upon in some detail:

Procedural fluency. For each new activity, we show 'how to', with the help of audio and the pointing hand, and other animation where appropriate. Instructions are kept simple and short, since lengthy audio instructions will be quickly forgotten. The work is usually scaffolded. We give instant feedback. We give sufficient repeats to ensure that the child has grasped the procedure. The modular structure of the software allows children to revisit topics and units as often as they wish. This is a further aid to procedural fluency. (V. Shimizu, Unlocking Talent, pers. comm., 05 November 2016)

It was of interest that the other three strands - although not the main emphasis of Unlocking Talent - were also commented upon:

Strategic competence. One could argue that all of the maths work is problem solving, including building models from 2-D shapes. We have examples of broader problem solving too, for example where the child must share food items equally between three hungry dragons. However, we formulate and represent the problems, not the child. We intend to build much more problem solving into future maths topics.

Adaptive reasoning. Our maths apps continually address the capacity for logical thought'. There is some scope for reflection, even if only in the brief pause after the positive or negative response to the child's input, and in the final audio summary of the work done in each unit. However, the child has no opportunity to explain and justify, unless another human intervenes.

Productive disposition. At these early stages, we do not explicitly promote maths as being sensible, useful and worthwhile. However, the child is likely to gradually become aware that maths makes sense. Its usefulness may become apparent particularly in the work on measurement (time, length, mass, capacity). The wealth of positive feedback - big ticks, congratulatory audio, the shooting-star finale at the end of each unit, the certificate at the end of each topic, and the final big banner - is likely to promote an inclination to see maths as worthwhile, and a belief in diligence and one's own efficacy. (V. Shimizu, Unlocking Talent, pers. comm., 05 November 2016)

We think that the above three descriptions from the project teams offer additional details about the approach to mathematics and the underlying learning theories guiding the content development. While how the technology is harnessed to support these learning approaches remains a consideration in most of the descriptions, we think that by asking for theories of learning, together with the prioritisation of particular strands of mathematical disposition, the identified gap - of an absence of attention to the mathematics and theoretical approaches to learning mathematics - was at least partially bridged. This was a relatively cost-effective and simple process, with the project teams willingly and timeously providing responses to our questions via email. We acknowledge that the above would require triangulation with other data sources (such as review of the content, analysis of uptake and usage data, and feedback from both teachers and learners) to be taken as accurate reflections of an actual approach to learning. Notwithstanding this limitation (as noted in the methodology), we consider the line of questioning to have been a useful undertaking in soliciting project team perceptions of underlying learning theories and approaches to mathematics.

\section{Discussion}

This article illustrates a data collection technique and applies a modified analytical framework for describing and comparing m-learing inverventions. In this section, 
we therefore briefly discuss what we observe when reflecting across the three exemplar cases. These observations and conjectures would require additional research to establish the extent to which these reflect more general trends in the m-learning field in the SADC region.

\section{How do these three exemplar Southern African Development Community projects map to the m-learning configurations?}

Figure 2 summarises how the three exemplar projects map to the m-learning configurations, with a detailed analysis thereafter.

In terms of the learning spectrum, in all the interventions the content covered is directly related to the formal curriculum and utilised in school. Mwabu is also used out-of-school but with the formal curriculum. Funding for such interventions tends to be tightly connected to the improvement of learning outcomes as they pertain to formal public schooling. We conjecture that designing for informal learning (conducted for pleasure or entertainment) would not be done on a free public access with zero subscription and zero data costs basis. We thus link this finding to affordability and access.

In the case of the kinetic spectrum, despite the fact that all the interventions are mobile-based, all three projects use the online materials in a classroom setting; thus, the users are stationary. This finding is interesting, as in setting up the m-learning configurations spectra, the mobile aspect of mobile devices was considered a key design feature. Having a mobile device assumed that this opened up the possibility to be using the device while moving and using it in more than one location and that this aspect would be harnessed by designers. In our three exemplar cases, however, none of the projects deliberately sought to use the fact that children can move with their devices. We conjecture that the motivation to use mobile devices may not have been in relation to

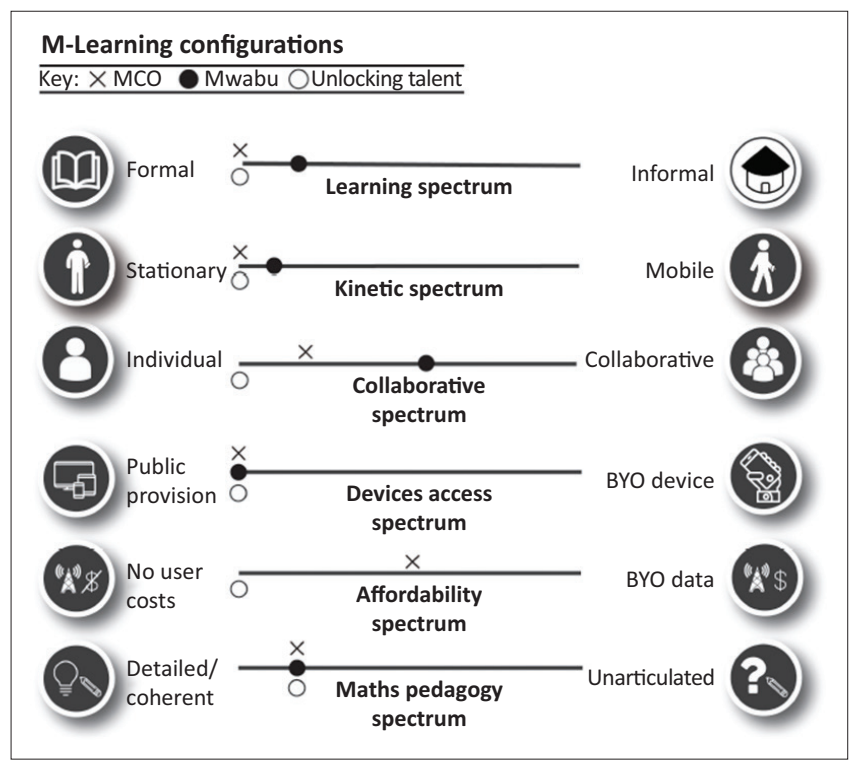

MCO, Mathematics Curriculum Online; BYO, Bring Your Own.

FIGURE 2: Mapping the case study interventions to the m-learning configurations. functionality (learners able to move) but rather was decided on the basis of cost. Mobile devices were more affordable than desktop or laptop devices, thereby increasing public access to the service. An interesting discussion about 'mobile moments' arose for Mwabu. Mobile moments refer to specific and explicit opportunity for children to move around in the classroom and work with concrete materials. While they were not moving with their devices, this movement and engagement is considered important for young children's learning.

With the collaborative spectrum, the materials provided in all the interventions have the potential to be used collaboratively but appear to more typically be utilised by individual users, though on occasions are used collaboratively (especially in the case with Mwabu). This is also of interest, as in the broader m-learning literature, the collaboration potential of mobile devices is considered a key configuration that allows for the creation of learning communities. However, in our three cases, the mobile device was not utilised for collaboration. In fact, when collaboration was encouraged, this was face-to-face within the class environment and not virtual. Collaboration (with two or more learners sharing one mobile device) was typically motivated by the access and affordability spectrum and not as a key design feature of mobile technologies. This is evident in the explanation provided about the collaboration aspect of Mathematics Curriculum Online: the weekly Brain Quests of the MCO project are usually collaborative - two to a device as a result of the limited number of devices. It was of interest that the project coordinator spontaneously commented that this collaboration has had 'very positive effects on the learning process'. Children of this age - certainly in resourceconstrained contexts - do not commonly personally own a mobile device. They are therefore gaining access to the device during a scheduled time slot during a school day, or in the case of one project, after school. We think this means that different kinds of design constraints are introduced and that the collaboration aspects of other mobile interventions may be less prevalent with this age group and target population.

We discuss the access and affordability spectra in turn. We are aware of numerous early grade m-learning interventions which expect personal ownership of devices, or paid-for data use, or charge for application download and as a subscription. These paid-for services target middle-class families who can afford their services. It is therefore noteworthy that, in terms of the affordability spectrum, in all three exemplar projects learners do not need to supply their own data. Similarly, with respect to the accessibility spectrum, all the devices required to access the materials are provided by the interventions or the schools in which the intervention happens. So, in all three cases, access is given via supplied devices, and there is no requirement for personal data purchase to access the services.

In the case of the mathematics pedagogy spectrum, there was no explicit or articulated pedagogy or approach to mathematics learning for any of the projects. By asking the project teams to describe this in 3-4 sentences, more detail 
on their underlying theoretical frameworks was solicited. The most common of the Kilpatrick et al.'s (2001) five strands of mathematical proficiency focused on in the three exemplar projects was 'procedural fluency', mentioned by all. Conceptual understanding was mentioned by two of the projects and productive disposition once. We conjecture that these areas of focus are, at least in part, a result of what the mobile technology platforms offer: immediate feedback on closed questions.

\section{Conclusion}

We trust that this article makes a contribution towards filling at least two identified gaps. Firstly, by describing three exemplar examples of m-learning interventions from the SADC region, we contribute to the m-learning literature from this under-researched and under-documented geographical region. It offers examples of how teachers and caring adults can be supported via mobile technologies in 'their instructional practices [of mathematics] to improve the lives of children in vulnerable circumstances' (Ebrahim \& Pascal 2016:2). Secondly, we put forward a modified analytical framework for describing m-learning interventions for critical review and application in other contexts.

In particular, we have distinguished the access from the affordability spectrum. The access spectrum includes more nuance with regard to shared access to devices, access to software and availability within or outside of school time. The affordability spectrum now considers various options for payment of data: by the individual; by the school, district or education department; or as a requirement of the national licensing conditions for mobile operators.

In addition, we have introduced a new spectrum relating to the mathematics pedagogy (making use of five strands of mathematical proficiency) in order to ensure that project descriptions relating to mathematics offer some information about their approach to mathematics and their theory of learning. In so doing, a process of refining robust approaches and tools for describing m-learning interventions is initiated.

We hope that the modified m-learning analytical framework will be used, adapted and improved, so that the m-learning field starts to have some common ways of approaching the descriptive component of m-learning work. We recognise that further research and contributions are required for the ongoing quest to have commonly-agreed metrics and approaches to measuring and reflecting on the efficacy of such interventions. Without broadly comparable descriptive details of exactly what each intervention entailed - how the m-learning was configured, the underlying pedagogy of the mathematics and then how the learners and their carers engaged with the m-learning intervention - lessons on how the promises of m-learning enhance or hinder educational outcomes will remain elusive.

\section{Acknowledgements Competing interests}

The authors declare that they have no financial or personal relationships that may have inappropriately influenced them in writing this article.

\section{Authors' contributions}

N.R. developed the expanded analytical framework. G.S.-S. did the bulk of the data collection. Both authors contributed equally to the writing of the article.

\section{Funding information}

The earlier research study, Spencer-Smith and Roberts (2014), on which this article was built, was published in October 2014 by the Deutsche Gesellschaft für Internationale Zusammenarbeit (GIZ) on behalf of and with funding from the German Federal Ministry for Economic Cooperation and Development (BMZ), as part of a series of landscape reviews published by members of the Mobile Education Alliance.

\section{References}

Bonk, C.J. \& Graham, C.R., 2006, The handbook of blended learning: Global perspectives, local designs, John Wiley \& Sons, Hoboken, NJ.

Chee, K.N., Yahaya, N., Ibrahim, N.H. \& Noor Hassan, M., 2017, 'Review of mobile learning trends 2010-2015: A meta-analysis', Educational Technology \& Society 20(2), 113-126.

Cheung, A.C.K. \& Slavin, R.E., 2013, 'The effectiveness of educational technology applications for enhancing mathematics achievement in K-12 classrooms: A metaanalysis', Educational Research Review 9, 88-113. https://doi.org/10.1016/ j.edurev.2013.01.001

Crompton, H. \& Burke, D., 2015, 'Research trends in the use of mobile learning in mathematics [Special Issue]', International Journal of Mobile and Blended Learning 7(4), 1-15. https://doi.org/10.4018/IJMBL.2015100101

Daher, W., 2010, 'Building mathematical knowledge in authentic mobile phone environments', Australasian Journal of Educational Technology 26(1), 85-104. environments', Australasian Journal
https://doi.org/10.14742/ajet.1104

Deloitte, Groupe Speciale Mobile Association (GSMA), 2012, Sub-Saharan Africa mobile observatory 2012, viewed 07 September 2016, from http://www. gsma.com/publicpolicy/wp-content/uploads/2012/03/SSA_FullReport_v6.1 gsma.com
clean.pdf.

Department of Basic Education (DBE), 2018, Mathematics teaching and learning framework for South Africa: Teaching mathematics for understanding, pp. 1-88, Government of South Africa, Pretoria.

Ebrahim, H. \& Pascal, C., 2016, 'Early care and education in disadvantaged contexts (birth to 9)', South African Journal of Childhood Education 6(2), a508, 1-2. https:// doi.org/10.4102/sajce. v6i2.508

Friedman, T., Schwantner, U., Spink, J., Tabata, N. \& Waters, C., 2016, Improving quality education and children's learning outcomes and effective practices in the Eastern and Southern Africa region. Nairobi: UNICEF, viewed 22 October 2018, from https://www.unicef.org/esaro/UNICEF-ACER(2016)QualityofEducationESAR-MainReport(SinglePageview).pdf.

Groves, S., 2012, 'Developing mathematical proficiency', Journal of Science and Mathematics Education in Southeast Asia 35(2), 119-145.

Guterres, A., 2018, The sustainable development goals report, United Nations, New York.

Johnson, L., Adams, S. \& Cummins, M., 2012, NMC horizon report: 2012 K-12 edition, Austin, TX: The New Media Consortium.

Kilpatrick, J., Swafford, J. \& Findell, B., 2001, 'The strands of mathematical proficiency'. in J. Kilpatrick, J. Swafford \& B. Findell (eds), Adding it up: Helping children learn mathematics, pp. 115-155, National Academy Press, Washington, DC.

Pitchford, D.N., 2014, Unlocking talent: Evaluation of a tablet-based Masamu intervention in a Malawian primary school, University of Nottingham, Nottingham, unpublished report.

Roberts, N., Spencer-Smith, G., Vänskä, R. \& Eskelinen, S., 2015, 'From challenging assumptions to measuring effect: Researching the Nokia Mobile Mathematics Service in South Africa', South African Journal of Education 35(2), 1-13. https:// doi.org/10.15700/saje.v35n2a1045 
Spencer-Smith, G. \& Roberts, N., 2014, Landscape review: Mobile education for numeracy. Evidence from interventions in low-income countries, GIZ, Bonn, viewed 15 May 2016, from http://www.giz.de/fachexpertise/downloads/bmzgiz2014-enlandscape-review-mobile-education-for-numeracy-long.pdf

Strigel, C. \& Pouezevara, S., 2012, Mobile learning and numeracy: Filling gaps and expanding opportunities for early grade learning, RTI International, Durham, NC, viewed 21 August 2015, from http://www.rti.org/pubs/mobilelearningnumeracy rti_final_17dec12_edit.pdf.

Thomas, K. \& Orthober, C., 2011, 'Using text-messaging in the secondary classroom', American Secondary Education 39(2), 55-76.

Traxler, J., 2009, 'Learning in a mobile age', International Journal of Mobile and Blended Learning 1(1), 1-12. https://doi.org/10.4018/jmbl.2009010101
Van Der Berg, S., 2015, 'What the annual national assessments can tell us about learning deficits over the education system and the school career', South African Journal of Childhood Education 5(2), 28-43. https://doi.org/10.4102/sajce.v5i2.381

Vosloo, S. \& Botha, A., 2009, 'Mobile learning: South African examples', Presented at Mobile Learning Institute Summit, Lusaka, Zambia, viewed 01 September 2016, from http://www.slideshare.net/stevevosloo/mobile-learning-south-african-examples.

Wong, B.T.M., 2018, 'Success in mobile and ubiquitous learning: Indicators of effectiveness', BRAIN: Broad Research in Artificial Intelligence \& Neuroscience 9(Special Issue), 55-63.

World Bank, 2018, World Bank country and lending groups, viewed 08 November 2018 from https://datahelpdesk.worldbank.org/knowledgebase/articles/906519-worldbank-country-and-lending-groups. 